\title{
PARA O INÍCIO DE UMA CONVERSA - A CRÔNICA NA SALA DE AULA
}

\author{
Ana Cristina Coutinho VIEGAS \\ Colégio Pedro II \\ anacristinaviegas@terra.com.br
}

\begin{abstract}
Resumo: A leitura em sala de aula pressupõe o estudo de diferentes gêneros textuais, entre os quais se encontram os gêneros literários. A formação estética dos alunos constitui um grande desafio para muitos professores da Educação Básica. O fortalecimento do ensino da literatura requer, contudo, maior aproximação entre as pesquisas acadêmicas e as práticas pedagógicas nas escolas. Em uma sociedade dominada por tecnologias visuais e pela cultura do entretenimento, é preciso rediscutir os objetivos de ensinar e estudar literatura, a relevância da educação literária e ainda o meio de fortalecer sujeitos sociais através da disciplina. Este trabalho se propõe a discutir a importância da crônica para a tarefa desafiadora de inserir crianças e jovens no mundo da leitura. Por suas próprias características, a crônica abre um caminho mais atraente para esse mundo além de funcionar como um incentivo à produção textual dos próprios alunos.
\end{abstract}

Palavras-chave: Crônica. Formação do leitor. Ensino de literatura.

Abstract: Reading in a classroom presupposes the study of different textual genres among which lies the literary one. The students' aesthetic formation constitutes a great challenge to a lot of Junior High School teachers. The encouragement to the teaching of literature requires, however, closer contact between the academic research and the pedagogical practices at schools. In a society in which the visual technologies and the entertainment culture prevail, it is necessary to re-discuss the objectives of teaching and studying literature, the relevance of literary education as well as a means of strengthening social subjects through the subject matter. This work aims at discussing the importance of the chronicle for the challenging task of inserting children and youngsters in the world of reading. Due to its own characteristics, the chronicle offers a more attractive way to reach this world besides working as an incentive to the students' own written texts.

Keywords: Chronicles. Reader formation. Teaching literature.

O conhecido desinteresse dos alunos da Educação Básica pela leitura do texto literário não pode ser explicado simplesmente como desprezo, rebeldia ou algo semelhante. Uma série de fatores é responsável por esse distanciamento. O objetivo deste estudo, porém, não é tecer considerações sobre esses fatores, mas sim buscar práticas que estimulem a leitura desse gênero textual. 
Algumas características das crônicas - textos breves, que tratam do cotidiano com uma linguagem menos formal - tornam esses textos mais atraentes para um leitor em formação. Não se trata, contudo, de uma atitude reducionista no que se refere ao ensino de literatura. Ao contrário, a crônica, ao dialogar com outros textos e permitir relações e inferências, constrói uma ponte para textos que requerem um leitor mais sofisticado, além de, muitas vezes, discutir questões diretamente ligadas aos estudos literários, propondo reflexões sobre o próprio ato de escrever.

O grande número de antologias recém-publicadas atesta a boa receptividade do gênero entre os leitores e evidencia sua relevância como objeto de estudo, embora ainda não conte com muito prestígio nos meios acadêmicos. O estudo da crônica na qualidade de texto literário esbarra em controvérsias entre os pesquisadores. Situá-la no limite entre a literatura e o jornalismo também não a resgata completamente de uma posição de texto menor. A pouca bibliografia sobre o gênero entre os estudiosos de literatura deixa entrever que se trata de um campo a ser mais explorado.

Apesar de seu veículo primeiro ser a imprensa, a crônica evita o espírito de reportagem. Para o jornalista, o fato constitui um fim, para o cronista, é apenas um meio. Na passagem do jornal para o livro, seu caráter circunstancial é amenizado, até mesmo porque aquelas que tendem ao envelhecimento não são incluídas nessas publicações. Se, por um lado, está ligada ao efêmero, por outro, tem o papel de preservar esse efêmero e pode até mesmo adquirir valor de documento de uma época. Existem, entretanto, outras maneiras de analisála. Uma dessas maneiras é considerá-la uma poderosa aliada no ensino de literatura.

\section{A crônica - fazendo gênero}

De acordo com diferentes críticos, a crônica, em seu sentido atual, constitui um gênero brasileiro pela originalidade com que aqui se desenvolveu. Ao longo de um percurso que vem da seção "Ao correr da pena", no Correio Mercantil, para a qual escrevia semanalmente José de Alencar, foi deixando de 
lado a intenção de informar e comentar - atribuída a outros textos que circulam na imprensa. Tornou-se mais leve, afastou-se da lógica argumentativa e penetrou no reino da poesia (CANDIDO, 1992).

De acordo com Margarida de Souza Neves, em seu artigo Uma escrita do tempo: memória, ordem e progresso nas crônicas cariocas,

\begin{abstract}
A crônica, pela própria etimologia - chronus / crônica -, é um gênero colado ao tempo. Se em sua acepção original, aquela da linhagem dos cronistas coloniais, ela pretende-se registro ou narração dos fatos e suas circunstâncias em sua ordenação cronológica, tal como estes pretensamente ocorreram de fato, na virada do século XIX para o século XX, sem perder seu caráter de narrativa e registro, incorpora uma qualidade moderna: a do lugar reconhecido à subjetividade do narrador. (NEVES, 1992, p. 82)
\end{abstract}

Os avanços da mídia eletrônica alimentam uma sociedade do espetáculo em que, cada vez mais, ganha espaço o falar de si. Em contrapartida, percebese um movimento teórico voltado para a problematização do sujeito nessa sociedade e, no que nos interessa mais de perto, na literatura. Esse pensamento vem acompanhado por um olhar atento na direção de gêneros considerados "menores" - como crônicas, diários e cartas - por permanecerem na fronteira entre o literário e o não literário, apontarem mais diretamente para a chamada "realidade" e constituírem discursos relacionados com o "eu" que escreve. Segundo Carlos Heitor Cony, "temos a crônica esportiva, a social, a policial, a política, a econômica. Elas se diferenciam do artigo porque são centradas num eixo permanente: o 'eu' do autor. Daí que o gênero é romântico por definição e necessidade" (CONY, 1998). A multiplicidade destacada por Cony - "esportiva", "social", "policial", "política", "econômica” - evidencia a necessidade de distinções mais apuradas, uma vez que as afinidades de muitos desses textos com a qualificação literária são mínimas (SIMON, 2004).

Quanto ao leitor, o pacto que se estabelece tem um caráter de maior referencialidade do que em outros gêneros como o romance. Mesmo assim, o cronista faz do seu texto um espaço para encenar uma subjetividade. Naquele espaço regularmente preenchido no jornal, constrói uma figura de autor que vai ganhando contornos de um cidadão comum, que mantém, em tom de conversa, uma certa intimidade com seu público. Este pode acompanhá-lo em 
ações cotidianas, como mostra o seguinte fragmento de uma crônica de Clarice Lispector, em que o leitor pode visualizar a autora em sua rotina de trabalho: "Esqueci de dizer que na casa tinha cachorro: cruza de galgo com vira-lata, muito manso e alegre. Vou interromper para tomar um café. Volto já." (LISPECTOR, 1999, p. 430).

A boa acolhida que o gênero tem recebido dos leitores brasileiros já foi constatada pelo menos há algumas décadas. Eduardo Portella, em texto publicado em 1958, ressalta:

A constância com que vêm aparecendo ultimamente os chamados livros de crônicas, livros de crônicas que transcendem a sua condição puramente jornalística para se constituir em obra de arte literária, veio contribuir, de forma decisiva, para fazer da crônica um gênero literário específico, autônomo. (PORTELLA, 1958, p. 111)

O Brasil pode-se considerar um país privilegiado no que diz respeito à quantidade de escritores consagrados que se voltaram para a produção de crônicas. Nomes como Carlos Drummond de Andrade, Clarice Lispector, Olavo Bilac, José de Alencar e Machado de Assis, entre tantos outros, aparecem nessa lista seleta. Sem deixar de mencionar Rubem Braga, que, excepcionalmente, publicou apenas livros de crônicas. De acordo com Carlos Heitor Cony, Rubem Braga justificava sua militância na crônica por condenar a falta de vida na imprensa em geral, ou seja, tudo que é veiculado nos jornais ou nas revistas, das condições do tempo ao desempenho das bolsas, deve ser "útil" ao leitor, aquilo que, nas redações, é chamado de "serviço" (CONY, 1998).

Mesmo tratando do trivial, muitas crônicas sugerem uma reflexão sobre grandes questões. Apesar de produzidas na pressa da escrita com hora marcada, constituem, em muitos casos, para usar uma metáfora de Caio Fernando Abreu, "joias encravadas no dia-a-dia".

\section{A crônica e a leitura na sala de aula}

Constitui papel fundamental de a escola ampliar e aprofundar a convivência dos alunos com a variedade e a complexidade dos gêneros textuais, entre os quais se encontram os gêneros literários. De modo geral, a 
educação literária visa desenvolver a sensibilidade do leitor para o artefato verbal através do desenvolvimento dos sentidos, da emoção e da reflexão, contudo tem também como finalidade contribuir para a promoção de uma consciência dos valores políticos e ideológicos que formam o gosto e o cânone.

A experiência com o texto literário pode ocorrer por meio de uma leitura que dá asas à imaginação e envolve emocionalmente o leitor, uma leitura crítica que possibilita discernir questões éticas, ideológicas, além de uma leitura capaz de perceber a construção do texto. Esses diferentes modos de ler podem e devem ser experimentados desde o Ensino Fundamental, visando à formação de um leitor autônomo.

Os Parâmetros Curriculares Nacionais situam o texto literário entre os diferentes gêneros discursivos a serem lidos na escola. Tendo como referência a LDB n. 9.394/96, os PCN entendem o estudo da gramática como uma estratégia para a compreensão, a interpretação e a produção de textos e integram a literatura à área de leitura. Sem indicar nenhum caminho para o letramento literário, dão a impressão de passar de um extremo a outro, ou seja, se havia gêneros e obras dignos de leitura, agora todas as leituras se tornaram equivalentes.

Faz-se necessário, cada vez mais, o diálogo entre a Universidade e a sala de aula da Educação Básica. É importante destacar que um diálogo pressupõe reciprocidade, isto é, os estudiosos de literatura precisam levar em conta, em suas pesquisas, as experiências com seu objeto de estudo nesse espaço de circulação social que é a escola.

Segundo Antonio Candido, a literatura pode formar, não no sentido pedagógico da palavra, mas como um dos meios através dos quais o jovem entra em contato com realidades que "se tenciona escamotear-Ihe" (CANDIDO, 1972). A leitura crítica e competente é fundamental para a cidadania e o fortalecimento do corpo discente requer a interseção entre as teorias dos estudos literários acadêmicos e uma pedagogia crítica.

Coleções como Para gostar de ler, da Editora Ática, lançada na década de 70, ainda estão em plena atividade nas salas de aula. Mesmo não se dedicando exclusivamente às crônicas, já que há alguns números voltados 
para os contos, a preponderância do gênero é indiscutível nessas décadas de publicação. É interessante lembrar também que os volumes dessa coleção exemplificam aqueles casos de livros mais lidos do que vendidos, dada sua penetração no ambiente escolar junto ao público infanto-juvenil (SIMON, 2004).

Outras coletâneas também ajudam a comprovar a boa receptividade do gênero nas salas de aula e bibliotecas escolares. Entre elas, estão as Comédias para se ler na escola, de Luís Fernando Veríssimo, que tiveram sua primeira edição em 2001, e as Crônicas para se ler na escola, de Carlos Heitor Cony, cuja primeira edição data de 2009.

Além da grande quantidade de antologias publicadas, os professores contam com uma relativa facilidade para elaborarem suas próprias coletâneas, visto que se trata de textos curtos. Se a escola não conta com um sistema de reprodução de cópias para as turmas, é possível levar jornais e revistas para as salas de aula ou fazer uma pesquisa na internet, já que muitas instituições escolares se encontram equipadas com computadores para uso dos alunos.

Outro aspecto que torna sedutor o trabalho com as crônicas é a brevidade desses textos, o que permite a leitura orientada pelo professor em poucos tempos de aula.

O planejamento de Língua Portuguesa no Colégio Pedro II distribui os gêneros textuais pelas séries da Educação Básica e prevê o estudo mais específico da crônica no oitavo ano. Nesse caso, destacamos outra faceta do emprego das crônicas como material didático. No Ensino Fundamental, a preocupação dos professores se concentra na leitura e em breve caracterização do gênero, visto que as discussões literárias só aparecem mais formalmente no Ensino Médio. Por outro lado, esses jovens leitores já possuem um repertório que Ihes permite criar suas próprias crônicas. Para incentivar essa produção, nada melhor do que proporcionar leitores para essas crônicas que não se restrinjam aos professores.

O Projeto Redação constitui uma das maneiras de dar visibilidade aos textos produzidos pelos alunos do Ensino Fundamental e Médio. Desde 2005, - Colégio Pedro II participa desse projeto viabilizado por uma parceria da Fundação Biblioteca Nacional com a Folha Dirigida. Anualmente, o número 
dedicado às redações dos alunos do colégio é composto por textos de diferentes gêneros selecionados pelos professores de Língua Portuguesa.

Para ilustrar, transcrevemos a crônica de uma aluna do oitavo ano da Profa. Flavia Vieira do Amparo (Campus Engenho Novo II), publicada na edição de 2007.




É muito importante criar situações reais de comunicação na tentativa de buscar soluções para uma das críticas feitas às condições escolares de produção textual que vem a ser o fato de desconsiderar o caráter interlocutivo do emprego da língua. Essas situações reais de comunicação tanto podem ser construídas em propostas mais estruturadas - como o Projeto Redação como em práticas pedagógicas mais cotidianas como a troca de textos entre os alunos ou o aproveitamento desses textos para atividades de estudos gramaticais entre tantas outras.

Se for grande a circulação desses textos entre os alunos da Educação Básica, a dificuldade de definição do gênero, contudo, também se estende ao material didático. Nos componentes curriculares de Língua Portuguesa do Projeto Político-Pedagógico do Colégio Pedro II (2002), por exemplo, a crônica aparece na relação de textos ligados à imprensa sem figurar entre os textos literários.

A própria dificuldade de caracterização, contudo, faz da crônica um texto privilegiado para discussões normalmente incluídas nos planejamentos e nos livros didáticos da primeira série do Ensino Médio, momento em que a literatura é apresentada como uma disciplina. Coleções de Literatura para o Ensino Médio invariavelmente dedicam suas primeiras páginas a distinções entre os textos literários e os não literários. As crônicas podem contribuir muito para essa discussão, que é bastante complexa nos estudos literários contemporâneos.

Além de sua importância na iniciação de jovens leitores, a crônica possibilita discussões no âmbito da teoria literária que estão previstas nos planejamentos do Ensino Médio. Esse aspecto, todavia, ainda vem sendo pouco explorado nos livros didáticos.

O escritor Bartolomeu Campos Queirós, no Manifesto por um Brasil literário, apresentado na Festa Literária Internacional de Paraty em 2009, lembra que:

Liberdade, espontaneidade, afetividade e fantasia são elementos que fundam a infância. Tais substâncias são também pertinentes à construção literária. Daí, a literatura ser próxima da criança. Possibilitar aos mais jovens acesso ao texto literário é garantir a presença de tais elementos - que inauguram a vida - como 
essenciais para o seu crescimento. Nesse sentido é indispensável a presença da literatura em todos os espaços por onde circula a infância (...) Se é um projeto literário, é também uma ação política por sonhar um País mais digno. (QUEIRÓs: 2009)

Se a imaginação vem a ser um instrumento para compreender o mundo e a nós mesmos, que futuro lhe está reservado nessa "civilização da imagem" (CALVINO, 1994)? Extrapolando finalidades meramente informativas, a literatura na folha de papel ou nas telas virtuais parece constituir um dos poucos espaços que restaram para a realização do nosso imaginário.

Em meio a tantas inovações industriais e tecnológicas, é preciso permanecer atento ao processo de mecanização do ser humano. A literatura cumpre papel fundamental no sentido de nossa humanização. Se o mundo capitalista tem como valor a "utilidade", a literatura, assim como as outras artes, se constrói no "desperdício" do qual o ser humano necessita. Fiquemos com Manoel de Barros, que, ao se definir como poeta, afirma: "porque eu não sou da informática: / eu sou da invencionática. / Só uso a palavra para compor meus silêncios" (BARROS, 2006)

É importante lembrar que a literatura é um produto acessível a consumidores dotados de certa competência, a qual tem sido desenvolvida basicamente pelo sistema de ensino. Além disso, a instituição escolar também reivindica um papel de consagradora, isto é, depois de um longo processo, canonizam-se determinadas obras pela sua inscrição nos programas didáticos. A esfera pública se compõe de diversos segmentos culturais e sociais, entre eles a escola, a qual funciona como um dos agentes de conservação e, simultaneamente, dinamização do cânone. Pesquisadores que se dedicam a pensar sobre o sistema literário não devem, portanto, ignorá-la.

Por fim, o principal argumento para se continuar a ensinar literatura na contemporaneidade é o de que a leitura literária é um direito de todos desde a infância. Ainda que o aluno não tenha interesse pelos textos literários, negar o contato com qualquer tipo de representação artístico-literária é privá-lo de exercer sua humanidade plenamente. E as crônicas, esses pequenos textos aparentemente despretensiosos, podem cumprir papel de grande relevância para esse exercício. 


\section{Referências bibliográficas}

BARROS, M. de. O apanhador de desperdícios. In: PINTO, M. da C. Antologia comentada da poesia brasileira do século XXI. São Paulo: Publifolha, 2006.

CALVINO, Í. Seis propostas para o próximo milênio. 2 ed. São Paulo: Companhia das Letras, 1994.

CANDIDO, A. A literatura e a formação do homem. In: Ciência e cultura. São Paulo. V. 24, n.9, 1972.

A vida ao rés-do-chão. In: CANDIDO, A. et al. A crônica: o gênero, sua fixação e suas transformações no Brasil. Campinas: UNICAMP; Rio de Janeiro: Fundação Casa de Rui Barbosa, 1992.

CONY, C. H. A crônica como gênero e como antijornalismo. Folha de São Paulo. 16 de outubro de 1998.

LISPECTOR, C. A descoberta do mundo. Rio de Janeiro: Rocco, 1999.

MEC/SECRETARIA DE EDUCAÇÃO MÉdIA E TECNOLÓGICA. Parâmetros curriculares nacionais. Ensino Médio. Brasília, 1999.

NEVES, M. de S. Uma escrita do tempo: memória, ordem e progresso. In: CANDIDO, A.et al. A crônica: o gênero, sua fixação e suas transformações no Brasil. Campinas: UNICAMP; Rio de Janeiro: Fundação Casa de Rui Barbosa, 1992.

PORTELLA, E. Dimensões 1. Rio de Janeiro: José Olympio, 1958.

QUEIRÓS, B. C. de. Manifesto por um Brasil literário. In: ASSOCIAÇÃO DE LEITURA DO BRASIL (org.). Bartolomeu Campos de Queirós - uma inquietude encantadora. São Paulo: Moderna, 2012.

SIMON, L. C. S. Do jornal ao livro: a trajetória da crônica entre a polêmica e o sucesso. In: Revista Temas e matizes. n. 5, 2004. Disponível em: http://www.unioeste.br/saber.

VIEGAS, Ana Cristina Coutinho et al. (org.). Projeto Redação 2007. Rio de Janeiro: Fundação Biblioteca Nacional / Folha Dirigida, 2007. 
Artigo recebido em: 30 de abril de 2013 Artigo aprovado em: 30 de maio de 2013

\section{Sobre a autora:}

Doutora em Letras (Ciência da Literatura) pela Universidade Federal do Rio de Janeiro (1998). 